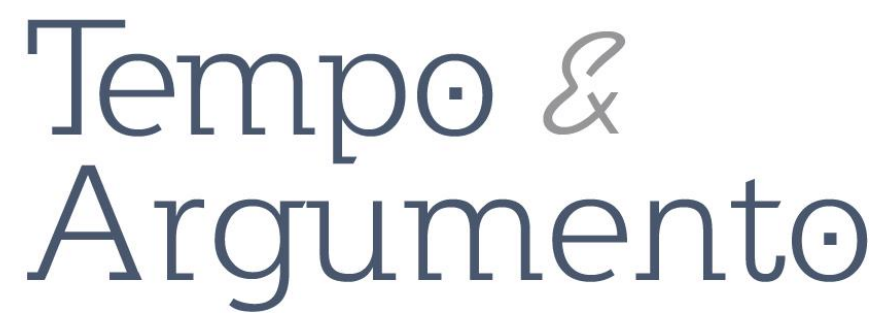

\title{
(Des)Caminhos da Mineração em Brumadinho: presente, passados e futuros
}

\section{Reinaldo Guilherme Bechler}

Doutor em História Contemporânea pela Julius-MaximiliansUniversität Würzburg - Alemanha. Estágio Pós-Doutoral em História da Ciência na Universidade Federal de Minas Gerais (UFMG). Estágio Pós-Doutoral em Educação Científica e Tecnológica na Universidade Federal de Santa Catarina (UFSC). Gerente Nacional de Projetos da Associação alemã de assistência aos hansenianos e tuberculosos, DAHW.

Brumadinho, MG - Brasil

reibechler@yahoo.com.br

orcid.org/0000-0001-7092-3773

\section{Rosiane Ribeiro Bechler}

Doutora em Educação pela Universidade do Estado de Santa Catarina (UDESC). Estágio Pós-Doutoral em História na Universidade do Estado do Rio de Janeiro (UERJ). Professora da Escola Estadual Paulina Aluotto Ferreira.

Brumadinha, MG - Brasil rosiribeirobechler@gmail.com orcid.org/0000-0001-7551-5533

Para citar este texto:

BECHLER, Reinaldo Guilherme; RIBEIRO, Rosiane. (Des)Caminhos da Mineração em Brumadinho: presente, passados e futuros [Debate]. Revista Tempo e Argumento, Florianópolis, v. 11, n. 26, p. 548 - 559, jan./abr. 2019.

http://dx.doi.org/10.5965/2175180311262019548 
Apresentamos aqui, em um esforço reflexivo, as memórias recentes sobre a tragédia criminosa ocorrida em Brumadinho no último dia 25 de janeiro deste ano, com o rompimento da Barragem 1 da Mina do Córrego do Feijão de propriedade da mineradora Vale S/A. Como moradores do município, mas, sobretudo como historiadores, buscamos olhar para esse crime na perspectiva de um "acontecimento nos limites" (RICOUER, 2008) e contrapondo os diferentes estratos do tempo (KOSELLECK, 2014) que o perpassam, preocupados com os desdobramentos dele advindos.

Para tanto o texto está organizado em três partes: na primeira, discorremos sobre as impressões e as emoções vivenciadas nos primeiros dias da tragédia; em seguida, situamos historicamente o desenvolvimento da atividade mineradora em Brumadinho; e, por fim, propomos algumas reflexões sobre as possibilidades e desafios que se apresentam ante a necessidade de reinvenção do município em diálogo com as contribuições possíveis da perspectiva da educação histórica e ambiental.

\section{A tragédia em seus primeiros dias}

Pessoal, recebi informação oficial aqui, é oficial do meu irmão que trabalha na Vale, estourou a barragem lá em Córrego do Feijão, um monte de gente já morreu, pra ninguém ficar perto do rio Paraopeba. (Autoria desconhecida, 25/01/2019. Áudio WhatsApp)

O áudio acima, que circulou entre os grupos de WhatsApp dos moradores de Brumadinho, foi a primeira notícia que recebemos do rompimento da Barragem 1 da Mina do Córrego do Feijão, em 25 de janeiro de 2019. Na sequência do áudio, foi partilhado também o link da reportagem publicada pelo Estado de Minas, “Barragem de rejeitos de minério da Vale se rompe em Brumadinho"1. A reportagem, quase que instantânea e por isso sucinta, apresentava ainda um quadro muito superficial da situação e ressaltava a preocupação com a população que vivia às margens do Paraopeba, e o pronto envio do Corpo de Bombeiros ao local, mas ainda sem apresentar qualquer estimativa do número

\footnotetext{
${ }^{1}$ Disponível em: https://www.em.com.br/app/noticia/gerais/2019/01/25/interna_gerais,1024468/barragemde-rejeitos-da-vale-se-rompe-em-brumadinho.shtml
} 
de vítimas. Destacava também que “em vídeos feitos no local, funcionários falam até em um restaurante atingido pela lama" (Estado de Minas, versão digital, 25/01/2019).

De Belo Horizonte, começamos a acompanhar, via imprensa e via amigos, dentre eles funcionários da Vale, os primeiros traços do quadro de mais uma tragédia na história da mineração em Minas Gerais. A sexta-feira foi, assim, marcada pelo desencontro de informações, pelo anseio de saber o que de fato havia se passado nos vales tomados pelas minas da Vale S/A. A preocupação com os trabalhadores, a busca por notícias, a peregrinação pelos hospitais, pautaram a tarde e a noite de um dia que parecia não ter fim. No Hospital João XXIII, onde fomos em busca de um amigo, a assistente social responsável pelas informações nos disse que estavam internados ali apenas cinco pacientes, e que ela mesma não estava entendendo a situação. Onde estavam as inúmeras vítimas da tragédia que tomou conta, com sua avalanche de lama, de toda mídia nacional?

Pelo receio das condições em que se encontrava o Rio Paraopeba e sem saber ao certo o que estava por vir ante a especulação de que a lama estava represando a água do do rio, optamos por passa a noite do dia 25 para 26 de janeiro em Belo Horizonte. No sábado pela manhã, nos colocamos a caminho de casa, atentos às atualizações partilhadas por amigos e pela imprensa, e certos de que um "acontecimento nos limites" (RICOUER, 2014) como aquele viria a abalar as mais diferentes estruturas da vida no município de Brumadinho.

A população brumadinhense adentrou o dia 26 de janeiro em um misto de ansiedade, de esperança e de mobilização. O quê, e quem havia ainda para ser resgatado? Qual a dimensão dos danos causados ao meio ambiente? Qual a dimensão das perdas humanas? Qual a dimensão do impacto material e imaterial que mais um crime da Vale S/A causaria a mais um dos territórios das Minas Gerais? Como historiadores que somos, essas perguntas já se delineavam para nós angustiando o pensar e aumentando o pesar diante da tragédia que se desdobrava em nossos arredores. Em nossas montanhas. Na vida de nossa gente.

Os veículos de imprensa, já em força tarefa, e literalmente acampados em Brumadinho, não davam a dimensão real da tragédia que, nos grupos de WhatsApp da 
cidade já se definia. "Por baixo, são 400 mortos", disse uma das pessoas com a qual cruzamos pelas ruas da cidade, que conhecia a região e boa parte dos funcionários da Vale. Mas imagens como a de Paloma, içada das margens do córrego do Feijão e a notícia das três pessoas encontradas vivas em uma caminhonete, mantinham acesa a esperança de outros salvamentos, ainda que dramáticos como estes. Além disso, a fala das autoridades que prontamente vieram "sobrevoar" a região, mas que se esquivaram do enfrentamento corpo a corpo com a miséria e a dor humana ali eminentes, construía a ilusória narrativa de que todos os esforços seriam envidados para o "bem de todos". Esforços que se estenderam até a peculiar negociação para a vinda do exército israelense e seus paramentos "ultramodernos" de detecção de calor e sondagem de equipamentos eletrônicos, utilizados com galhardia em contextos extremos de guerras e/ou catástrofes naturais como terremotos na referida região. Mas em Brumadinho? Na lama? Com qual calor, quatro dias depois do crime?

Às margens, nós acompanhávamos as movimentações da cidade. Pela manhã, notícias de salvamentos que poderiam ser cinematográficos, quase fictícios, não fosse a realidade dura que se impunha. Uma caminhonete resgatou cerca de 20 funcionários que se atropelavam para alcançar um lugar no veículo, enquanto viam seus colegas engolidos pela lama. Na parte da tarde, chegavam novos relatos de amigos que, por trabalharem na Vale ou por serem figuras públicas, tiveram acesso ao local devastado pelo rompimento da Barragem 1 da Mina do Córrego do Feijão. Relatos de pessoas igualmente devastadas, contando sobre um mar de corpos despedaçados naquele mar de lamas. A podridão humana literal e figurativa. Enquanto isso, na imprensa, eram divulgadas incansavelmente as imagens de resgates cuidadosamente selecionadas e números completamente desencontrados.

Foi assim que o segundo dia da tragédia-crime da Vale S/A em Brumadinho transcorreu entre as horas intermináveis perpassadas pela guerra de narrativas jà deflagrada. Dentre elas, as imagens partilhadas que escancaravam a destruição, o desamparo, o despreparo, o desrespeito e tantos outros "des" que podem servir para 
qualificar o teatro de horrores sobre esse mar de lama tóxica que devastou patrimônios materiais e imateriais das gentes brumadinhenses. E o caos estava só se delineando.

O domingo, 27/01, começou cedo na sede de Brumadinho. Por volta das 5h30 da manhã, sirenes foram tocadas e carros com seus alto-falantes despertaram os brumadinhenses que, de fato, não dormiam desde a última sexta-feira. O alerta era em relação ao risco do rompimento da barragem de água (B6), também na Mina de Córrego do Feijão, cuja estrutura havia sido comprometida pelo desabamento da barragem de rejeitos (B1). A notícia começou a circular quase instantaneamente na rádio, na TV e, como não poderia ser diferente, nos grupos de WhatsApp, sendo que nestes, o risco variava entre o real rompimento da barragem até suposições de que o alerta era só um "teste" da Vale S/A.

O cenário de caos se agravava com as informações imprecisas controladas pela Vale S/A, com a assistência precária às pessoas afetadas e particularmente aos familiares das vítimas. Somavam-se a isso os receios dos impactos ambientais particularmente na vida do Rio Paraopeba.

Foi assim que entre as primeiras horas da manhã e as $15 \mathrm{~h}$ da tarde, as buscas pelas vítimas da tragédia e a rotina dos moradores das consideradas "áreas de risco" seguiu suspensa. No decorrer do dia, o desespero de toda uma população e principalmente dos familiares dos desaparecidos, só aumentava resultante do confronto direto entre esperança e angústia. A dimensão real do crime da Vale S/A em Brumadinho começava a ganhar contornos que não poderiam mais ser escondidos. A suspensão das buscas significou também a suspensão da esperança de encontrar centenas de pessoas com vida e a constatação relutante da extensão dos danos causados por aquela tragédia criminosa.

A partir de segunda-feira, 28/01, o luto e a luta passaram a conviver nas ruas da cidade. E, para nós, a discussão teórica proposta por Paul Ricouer (2008, p. 269) ao analisar a representação historiadora em suas particularidades e limites a partir da "solução final" passou a ecoar em seu sentido profundo, apontando a responsabilidade que se imporia a partir de então. De acordo com o autor, 
(...) tanto quanto o historiador, é o cidadão que é solicitado pelo acontecimento. Solicitado ao nível de sua participação na memória coletiva, diante da qual o historiador é chamado a prestar contas. (RICOUER, 2008, p. 271)

\section{A mineração em Brumadinho - olhares sobre um passado nem tão distante}

Com uma área aproximada de 639,434km², é o quarto maior município em extensão territorial de Minas Gerais - maior inclusive que Belo Horizonte, e sua população estimada é de 39.000 habitantes. Destes, cerca de 7.000 residem na Zona Rural do município e o restante na Sede. O município agrega os distritos de Aranha, Piedade do Paraopeba, São José do Paraopeba e Conceição do Itaguá. Semelhante ao que se observa em outros municípios de Minas Gerais, Brumadinho tem na indústria mineradora seu principal motor (cerca de $60 \%$ da arrecadação fiscal, fora os valores que, advindos da renda dos trabalhadores da Vale S/A movimentam os setores de serviços e comércio).

Imagem 1-Brumadinho em escalas

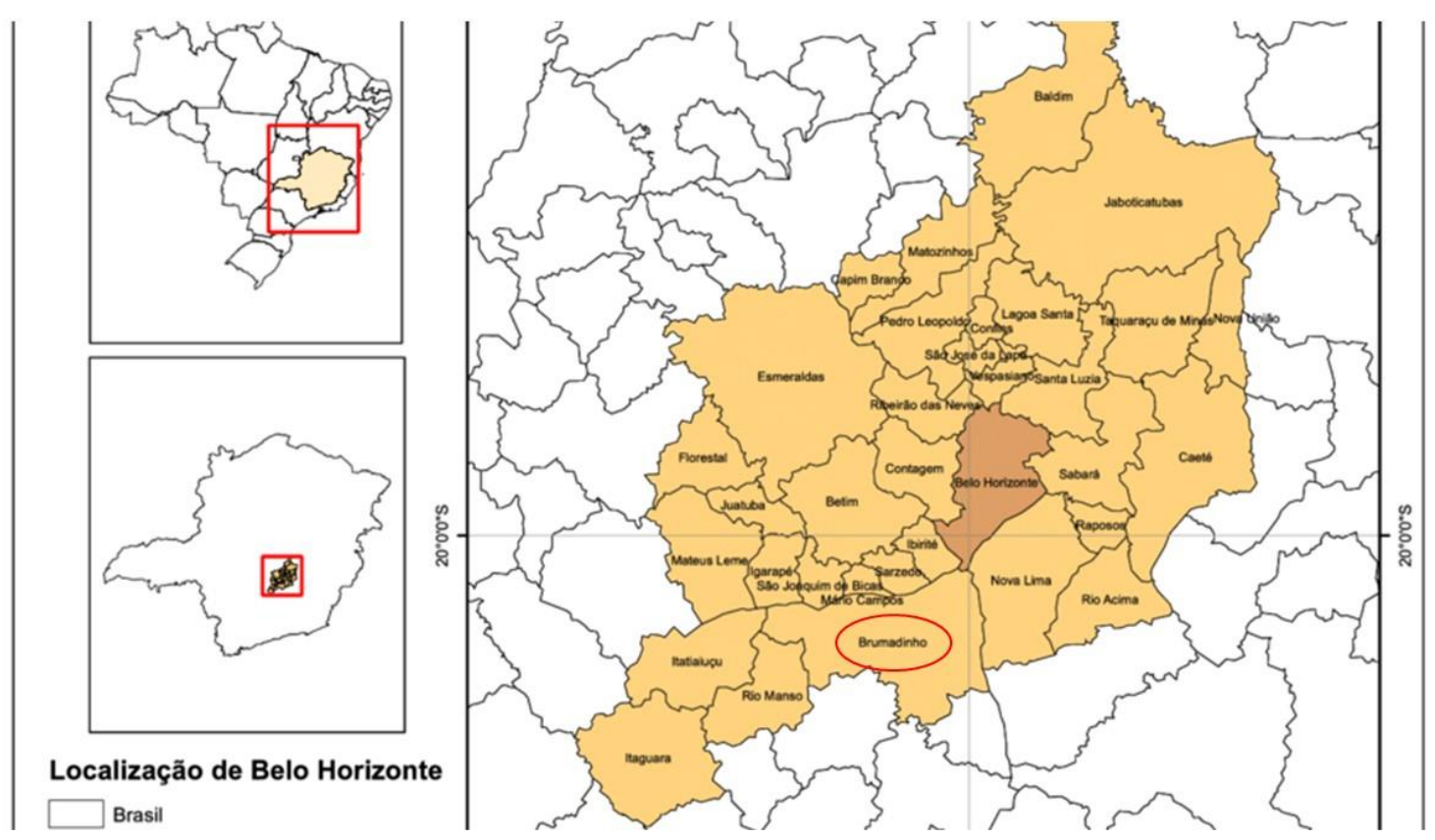

Fonte: https://www.researchgate.net/figure/Figura-1-Mapa-de-Localizacao-do-municipio-de-BeloHorizonte_fig1_319411324 
A história do Ciclo do Ouro também deixou seus lastros na história brumadinhense, fazendo coincidir o início da formação histórica do município com a chegada de bandeirantes paulistas, desconsiderando assim as dinâmicas sociais e econômicas já estabelecidas no território pelas comunidades indígenas que ali habitavam. Cabe registrar que a relação estabelecida e reafirmada nas narrativas da historiografia, que toma de assalto a História de Minas Gerais como correspondente à História do Brasil Colônia, confere à mineração o lugar da opulência, legitimado pelos tempos da exploração aurífera na Minas colonial (e pelo sentido que conferimos a ele). Essa compreensão encobre outras dinâmicas sociais, econômicas e culturais do território mineiro, assim como silencia a devastação que hoje, ainda mais do que no passado, se vincula à atividade mineradora desenvolvida de maneira predatória no espaço-tempo das Minas Gerais.

De acordo com a narrativa histórica ainda legitimada, bandeirantes orientados por Fernão Dias Paes Leme, iniciaram, ao final do século XVII, a ocupação da região do Espinhaço Meridional, local onde hoje se situa o município de Brumadinho, em busca da sonhada "Serra das Esmeraldas".

Nos séculos que se seguiram, os pequenos lugarejos fundados como ponto de abastecimento de víveres nos caminhos abertos pelos bandeirantes foram configurandose como um pequeno arraial de mineradores, em decorrência da descoberta das grandes reservas de minério de ferro características da região. O município de Brumadinho compõe o denominado “Quadrilátero Ferrífero" que compreende o complexo geológico localizado no centro-sul de Minas Gerais, de onde é extraída 60\% de toda produção de ferro do país.

Em 20 de junho de 1917, foi inaugurada a Estação Brumadinho, dando início ao povoamento ostensivo da região. No mesmo dia 20 de junho, foram inauguradas as Estações de Belo Vale, Fecho do Funil, Sarzedo, Ibirité, Jatobá e Gameleira, concluindo o trecho do Paraopeba. Moeda, Souza Noschese e Inhotim que foram inauguradas em 1919, 1925 e 1934, respectivamente. As alterações espaciais e de dinâmica social geradas pela inauguração desse grande complexo ferroviário, acabaram culminando com a criação do município de Brumadinho, em 1938, pelo decreto Lei nº.148, de 17 de dezembro. Este, até então, pertencia ao município de Bonfim na qualidade de distrito. Assim, podemos 
perceber que a construção do ramal do Paraopeba marca a segunda fase da formação histórica de Brumadinho, vinculada simbólica, política, social, econômica e culturalmente às estações ferroviárias de seu entorno e à extração de suas riquezas minerais.

Foi nesse mesmo período, em meados do século $X X$, que a atividade mineradora desenvolveu-se de maneira acelerada e intensa, uma vez que a construção do ramal e das estações ferroviárias passou a interligar distritos e povoados do município de Brumadinho e seu entorno, entre si, e com a região metropolitana de Belo Horizonte, facilitando o deslocamento das pessoas e o transporte do minério de ferro. Sendo que ao final da década de 1980, o segundo veio a suprimir o primeiro, e as linhas férreas do complexo do Paraopeba passaram a levar apenas as nossas montanhas transfiguradas em pedras de minério.

As primeiras atividades relacionadas à Mina do Córrego do Feijão reportam ao ano de 1941, quando a Companhia de Mineração de Ferro e Carvão S/A conseguiu autorização do poder executivo federal para pesquisar a existência de minério de ferro na região. De acordo com o decreto:

Art. $1^{\circ}$ Fica autorizada a companhia de Mineração de Ferro e Carvão S. A. a pesquisar minério de ferro numa área de duzentos e dezesseis hectares trinta e dois ares e cinco centiares $(216 \mathrm{Ha} 32 \mathrm{a} 5 \mathrm{ca})$ no lugar denominado "Córrego do Feijão", distrito de Piedade do Paraopeba, município de Nova Lima, Estado de Minas Gerais, área essa delimitada por um polígono tendo um vértice coincidindo com o Alto dos Três Irmãos (...) (Decreto $n^{\circ} 7442$ de 25/06/1941)

Posteriormente, o distrito de Piedade do Paraopeba passou a fazer parte do município de Brumadinho e a referida companhia também passou a funcionar sob a denominação Ferteco Mineração S.A. Foi essa empresa, de capital germânico controlada pela ThyssenKrupp Stahl AG (TKS), a responsável pela construção da barragem de rejeitos com a técnica de alteamento a montante na Mina do Córrego do Feijão, no final da década de 1970. Foi em 2001 que a Companhia Vale do Rio Doce S.A., estatal privatizada em 1997 durante o governo de Fernando Henrique Cardoso, comprou a Ferteco e assumiu o controle sobre as minas geridas pela TKS. Prosseguindo com a extração de minério de maneira cada vez mais predatória, e aumentando o depósito de rejeitos para além da 
capacidade suportada pelas barragens, que contribuiu com as tragédias-crime de Mariana, em 2015, e de Brumadinho, em 2019 - isso para citar apenas dois exemplos de maior projeção.

Atualmente, as principais empresas do ramo minerário atuantes em Brumadinho são: a Vale S/A, a Ferrous Ressource do Brasil (adquirida recentemente pela Vale), a Mineral do Brasil (MIB) e a Tejucana Mineração S/A. Importante destacar que a atividade mineradora, dado o peso econômico que assumiu no município de Brumadinho marcadamente na segunda metade do século $X X$, suspendeu as dinâmicas espaciais em favor de seu beneficiamento muito antes da tragédia do dia 25 de janeiro.

E essa suspenção fica clara no abandono e descaso observados com o espaço público e nas relações conflituosas entre os vínculos familiares e os vínculos comunitários sobrepostos nas dinâmicas político-sociais. No meio do caminho, o rompimento da barragem 1 da Mina do Córrego do Feijão veio a descortinar antigas chagas e abrir novas feridas nas relações das gentes brumadinhenses com suas territorialidades.

\section{No curso do mar de lamas um caminho das lutas que se iniciam}

Uma das ideias e comentários que mais nos tocou, já nos dias subsequentes ao crime, era a de que "a cidade havia acabado". Afinal, o que seria do município que tem na mineração quase $70 \%$ de sua arrecadação bruta? Sendo praticamente 50\% apenas da Mina do Feijão, da Vale. O movimento de construção dessa narrativa nos moveu, como historiadores. Tínhamos que nos posicionar.

Não. Brumadinho não acabou, e nem vai acabar. Mas, mais do que apontar as muitas belezas naturais da região, suas potencialidades comerciais, industriais e mesmo turísticas, pretendemos suscitar aqui uma reflexão mais ampla.

Em primeiro lugar, chamar a atenção para as muitas demandas de trabalho na região, conclamando academia, poder público e privado a propor soluções concretas a eles. Afinal, apenas na escola de nossos filhos, contamos em quase quarenta, as crianças órfãs; apenas entre nosso círculo de amizades/família contamos em dezenas os jovens que 
veem não apenas seus amigos e/ou familiares soterrados, mas também seus sonhos profissionais, já que trabalhar na Vale era uma grande honraria local. Isso, claro, sem contar as inquietantes perspectivas ambientais e mesmo de saúde-pública que envolvem a região como um todo. O que se pode fazer?

Nossa ação inicial está sendo a de atuar na construção in loco de uma narrativa menos pessimista nos círculos sociais, acadêmicos e políticos em que atuamos. Por mais piegas que possa parecer, consideramos tal ação um ato de resistência. Nos esforçamos para mostrar que o crime não pode e não vai nos sobrepujar. A cidade tem uma história anterior e um futuro posterior a essa empresa.

Ao mesmo tempo, é imperioso constatar que a Brumadinho que conhecemos, de fato, não existirá mais. Precisamos deixar para trás aquela Brumadinho da Vale, a dos caminhões de minério disputando cada palmo do chão do município com os turistas do famigerado Museu de Inhotim que, via de regra, mal abriam o vidro de seus carros ao passar pelas ruas empoeiradas ou, no caso "emineriadas".

Estamos querendo dizer que a relação da cidade e de sua gente com o minério e com a mineração precisa se modificar, mas não sem esforços e disputas. Consideramos que nos "estratos do tempo" (KOSELLECK, 2014) da história do município as camadas da atividade minerária sobrepõem-se a outros paradigmas possíveis para desenvolvimento econômico, cultural e mesmo político. Nessa perspectiva, é uma utopia considerar que, em um espaço médio de tempo, o município conseguirá sobreviver apenas com o turismo, por exemplo.

Cientes desses desafios, o que pleiteamos é uma participação social mais ampla de sua gente na tumultuada relação envolvendo empresas mineradoras, classe trabalhadora, poder público. Da lama, precisa brotar uma nova relação da atividade mineradora com os locais “minerados”, e Brumadinho pode contribuir muito nessa discussão. Que saibamos construir ambientes para essa contribuição diferentes dos que fizemos - ou tentamos fazer - em Mariana. Nesse contexto, o presente texto pretende conclamar especialmente a assim denominada "academia" a não apenas pensar soluções, mas concretizar soluções para esses problemas sumariamente aqui apontados. Universidade sem conexão com a 
sociedade em que se insere é estéril, é pueril, é fracassada. E, arriscamos dizer, poucos objetos de intervenção acadêmica serão tão paradigmáticos para que se discuta a relação ciência/sociedade no Brasil do que Brumadinho atualmente.

Em segundo lugar gostaríamos de salientar o ponto de vista da educação nesse processo. Seu papel transformador, questionador, ao mesmo tempo em que fazemos uma mea culpa quanto a sua omissão frente a todo o contexto político e social que ocasionou o crime da Vale no 25 de janeiro de 2019. Conjugar o verbo “educar” na lama de Brumadinho é um exercício singular, e que demanda muita coragem. No encerramento dessas reflexões que nos levam a novos começos, retomamos o dilema proposto por Hannah Arendt, ao pontuar que

A educação é assim o ponto em que se decide se se ama suficientemente o mundo para assumir responsabilidade por ele e, mais ainda, para o salvar da ruína que seria inevitável sem a renovação, sem a chegada dos novos e dos jovens. A educação é também o lugar em que se decide se se amam suficientemente as nossas crianças para não as expulsar do nosso mundo deixando-as entregues a si próprias, para não lhes retirar a possibilidade de realizar qualquer coisa de novo, qualquer coisa que não tínhamos previsto, para, ao invés, antecipadamente as preparar para a tarefa de renovação de um mundo comum. (ARENDT, 2000, p. 247)

$E$, nesse limite do acontecimento marcado pela tragédia e pelo crime, decidimos que amamos sim, suficientemente, o mundo e as nossas crianças.

E por isso assumimos o compromisso de, como historiadores e educadores, "prestar contas" à sociedade, como colocado por Paul Ricouer (2014). E como cidadãos, de nos engajarmos nessa luta que é cotidiana e em diferentes frentes de atuação, nos espaços plurais que ocupamos. Certos de que, se "Eu Luto - Brumadinho Vive"2.

\section{Referencias}

\footnotetext{
${ }^{2} \mathrm{O}$ "Eu Luto - Brumadinho Vive" é uma articulação formada por pessoas impactadas pelo crime da Vale em Brumadinho, que tem como pauta central a garantia do protagonismo, da centralidade e da autonomia local nesse processo de embates e decisões que nos conclamam a tomadas de atitude no curto, médio e longo prazo. Nos organizamos em um Grupo Referência, do qual fazemos parte, e em sete grupos de trabalho temáticos: Educaçao (que também integramos), Memória, Comunicação, Articulação Social, Apoio Jurídico, Saúde e Meio Ambiente e Tech. Nossos canais de comunicação por enquanto são via Facebook (www.facebook.com.br/eulutobrumadinhovive) e pelo Instagram (@eulutobrumadinhovive).
} 
ARENDT, Hannah et al. A crise na educação. Entre o passado e o futuro, v. 5, p. 221-247, 2000. Disponível em: http://www.gestaoescolar.diaadia.pr.gov.br/arquivos/File/otp/ hanna_arendt_crise_educacao.pdf Acesso: 13 abr. 2019.

KOSELLECK, Reinhart. Estratos do tempo. Estudos sobre história. Tradução de Markus Hediger. Rio de Janeiro: Contraponto PUC Rio, 2014.

RICOEUR, Paul. A história, a memória, o esquecimento. Campinas: Unicamp, 2008. 